\title{
Hyperkeratotic necrobiosis lipoidica
}

\author{
Farhan Khan, M.D. ${ }^{1}$, Marigdalia K. Ramirez-Fort, M.D. ${ }^{1}$, C. Stanley Chan, M.D. ${ }^{2}$, \\ Theodore Rosen, M.D. ${ }^{2}$
}

${ }^{1}$ Center for Clinical Studies, Houston, TX, USA
${ }^{2}$ Department of Dermatology, Baylor College of Medicine, Houston, TX, USA

Keywords: necrobiosis lipoidica, granulomatous inflammation

Citation: Khan F, Ramirez-Fort MK, Chan S, Rosen T. Hyperkeratotic necrobiosis lipoidica. Dermatol Pract Conc. 2013;3(1):4. http:// dx.doi.org/10.5826/dpc.0301a04.

Received: July 31, 2012; Accepted: December 1, 2012; Published: January 31, 2013

Copyright: $@ 2013$ Khan et al. This is an open-access article distributed under the terms of the Creative Commons Attribution License, which permits unrestricted use, distribution, and reproduction in any medium, provided the original author and source are credited.

Funding: None.

Competing interests: The authors have no conflicts of interest to disclose.

All authors have contributed significantly to this publication.

Corresponding author: Farhan Khan, M.D., Center for Clinical Studies, 6655 Travis, Suite 120, Houston, Texas 77030, USA. Tel. 713.528.8818. Fax.713.528.8848 E-Mail: fkhan@ccstexas.com.

\section{Case report}

A 56-year-old Caucasian male with a history of uncontrolled diabetes mellitus and multiple other comorbidities was evaluated for slowly expanding plaques of his right lower leg, left forearm and left dorsal hand that had been present for the past six years. The patient denied any associated pruritus or pain. There was no history of previous trauma, immunosuppression, recent travel or prior treatment of the areas. His most recent laboratory values were significant for a hemoglobin A1c (HbA1c) of $8.9 \%$.

Physical examination revealed annular waxy brown plaques with central atrophy and a lilac colored advancing edge located on the left posteriorlateral calf measuring $5 \times 4 \mathrm{~cm}$, left dorsal hand $5 \times 3.5 \mathrm{~cm}$, and left forearm $11 \times 9 \mathrm{~cm}$ (Figure 1). Interestingly, a 5.5 $\mathrm{x} 4.5 \mathrm{~cm}$ plaque on the right anterior

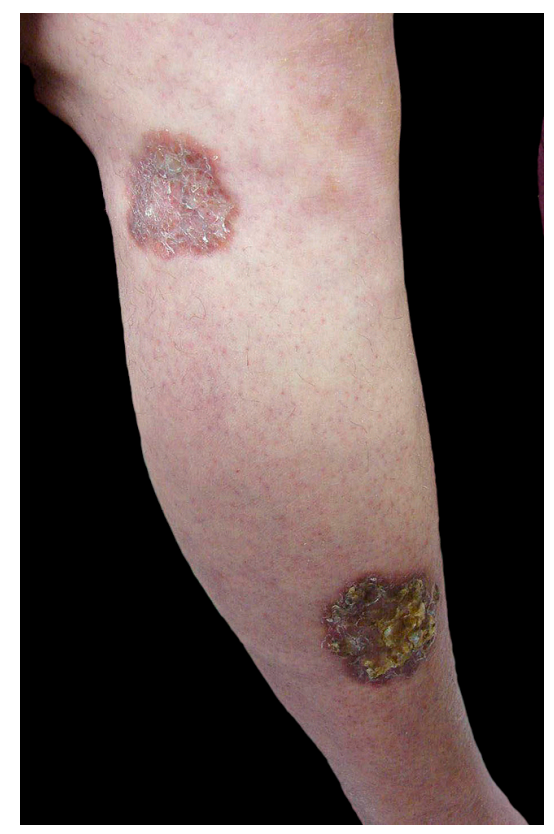

Figure 1. Two of the reddish-brown plaques on the leg. Note the difference in their clinical appearance. [Copyright: (2013 Khan et al.]

lower leg exhibited central hyperkeratosis as opposed to atrophy (Figure 2). A punch biopsy of the atrophic plaque on the left forearm was performed, which revealed granulomatous inflammation with epithelioid granulomas and plasma cells. Periodic acid-Schiff, Gomori's methenamine silver, acid-fast bacteria and Fite stains were negative for organisms. A subsequent biopsy of an adjacent area demonstrated an attenuated epidermis with diffuse and palisaded granulomatous inflammation within the deeper levels of the dermis (Figure 3). The inflammatory infiltrate was composed of lymphocytes and histiocytes, admixed with scattered perivascular plasma cells (Figure 4). There was minimal increase in interstitial mucin. Bacterial, fungal and acid-fast bacteria cultures for the second biopsy remained negative. The diagnosis is that of necrobiosis lipoidica (NL). The lesions were treated with topical emollients and clobetasol ointment once daily. After one month of treatment the patient reported improved appear- 


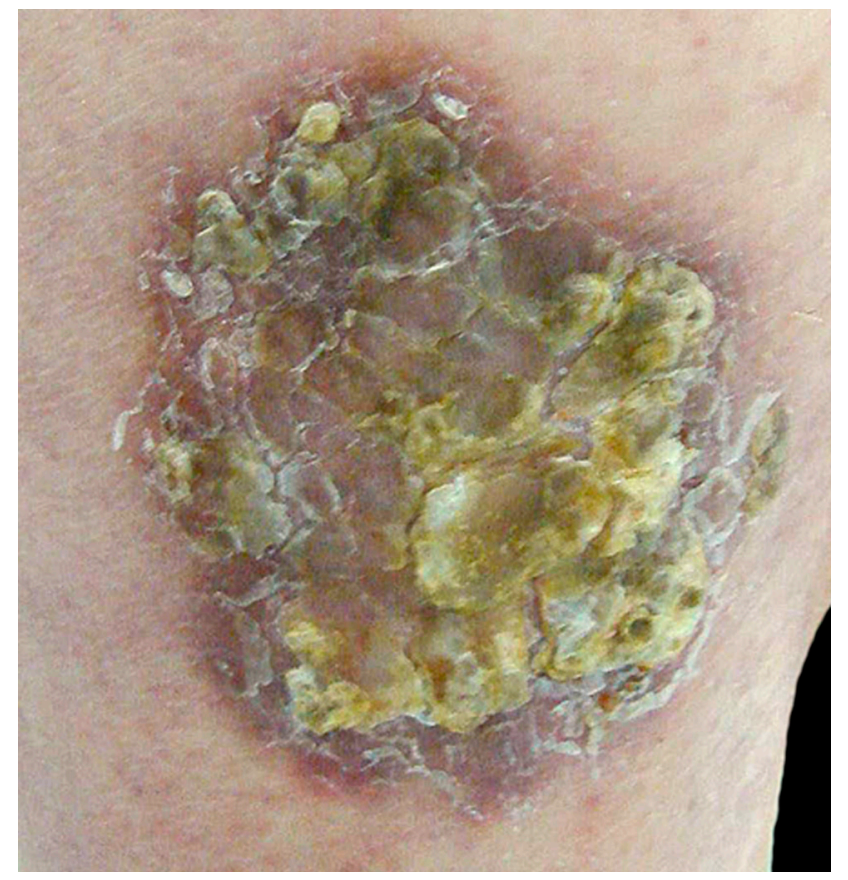

Figure 2. Hyperkeratotic scaling of the plaque on the right anterior shin. [Copyright: @2013 Khan et al.]

ance of all lesions including the hyperkeratotic one, with no increase in size of the plaques.

\section{Discussion}

Necrobiosis lipoidica was first described by Oppenheim in 1929, and he named it dermatitis atrophicans diabetica [1]. Today however, the preferred name is necrobiosis lipoidica due to its prevalence in a significant number of non-diabetic patients [2].

Necrobiosis lipoidica is a rare degenerative connective tissue disease of unclear etiology [3]. This disease is more common in females with a female-to-male ratio of approximately 3 to 1 [3]. It has been estimated that up to $65 \%$ of patients with necrobiosis lipoidica have underlying diabetes mellitus [2]. However, only $0.3 \%$ of patients with diabetes mellitus have necrobiosis lipoidica [7]. Diabetic patients with necrobiosis lipoidica do appear to have a higher rate of diabetes-related complications [6].

Necrobiosis lipoidica classically presents as a red-brown papule that slowly progresses into yellow-brown, telangiectatic plaques surrounded by raised, violaceous rims $[2,3]$. The plaques often develop central epidermal atrophy [4]. Oftentimes, scattered hyperkeratotic plugs and superficial telangiectasia are noted [2]. It is usually seen with bilateral symmetry of the pretibial region and less commonly it may affect the upper extremities, face, and scalp [6]. Ulceration is the most common complication and may occur in up to $35 \%$ of patients [4].

There are two distinct histological patterns in necrobiosis lipoidica, both with isolated dermal pathology. The necrobi-

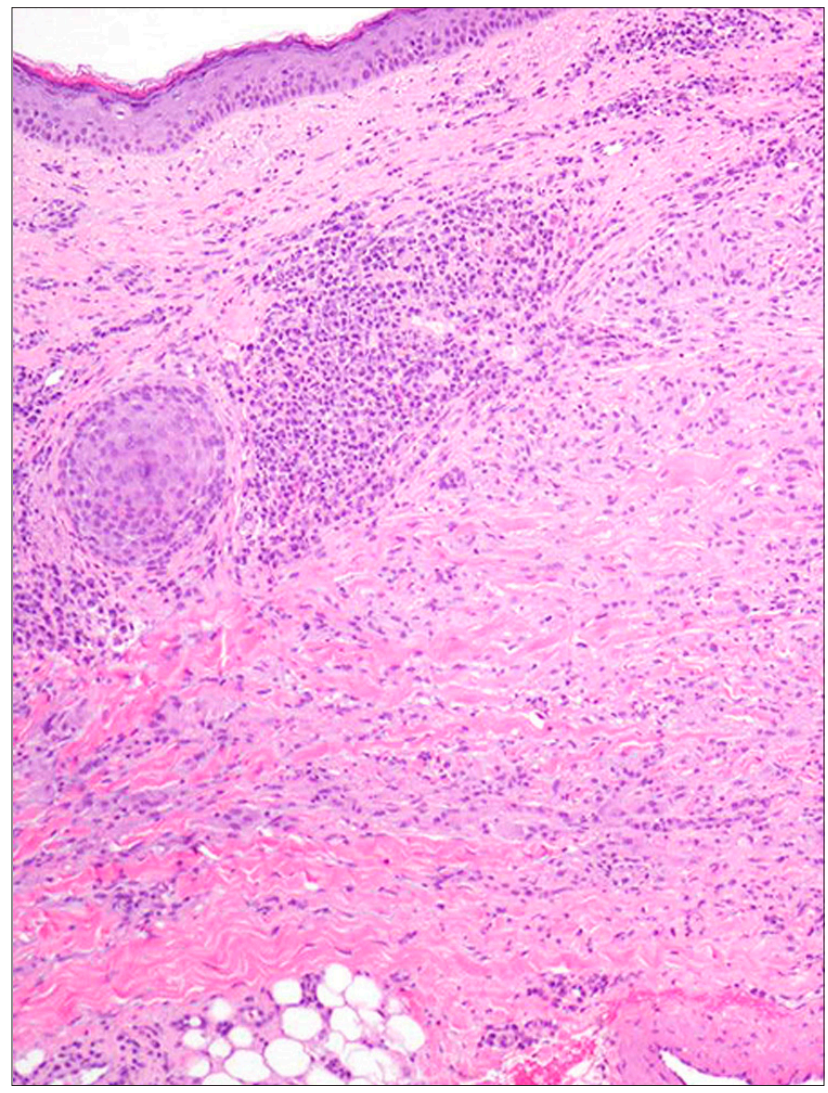

Figure 3. An interstitial granulomatous dermatitis aligned parallel to the skin surface (H\&E, original magnification 100x). [Copyright: (C)2013 Khan et al.]

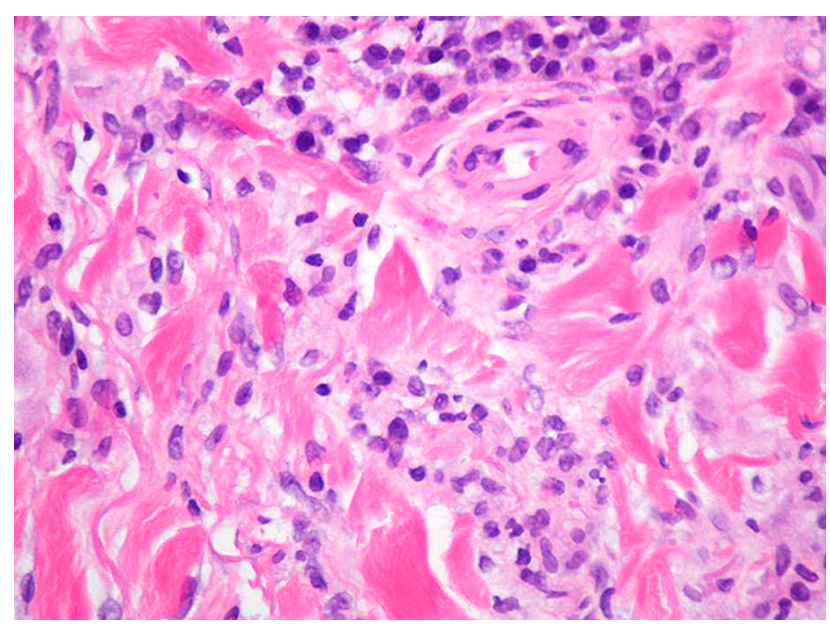

Figure 4. A mixed perivascular infiltrate composed of lymphocytes and histiocytes with plasma cells (H\&E, original magnification 400x). [Copyright: (2013 Khan et al.]

otic pattern is usually present in patients with diabetes and the granulomatous pattern is more common in non-diabetic patients [2]. In both types, the epidermis is usually normal with the dermis being affected.

There have been a few cases of unusual presentations of necrobiosis lipoidica in the literature. Parra, in 1977, first reported three cases of perforating necrobiosis lipoidica in which transfollicular elimination of degenerated collagen appeared clinically as hyperkeratotic papules on the surface 
of the plaques [8]. Perforating necrobiosis lipoidica is rare and only a few cases have been described in the literature [9-13]. Michaels and Mullinax et al reported a case of tuberous necrobiosis lipoidica in which they observed yellow nodules, reminiscent of tuberous xanthomas, superimposed on patches of necrobiosis lipoidica [14]. These nodules eventually coalesced and grew more nodular and verrucous over time. Joshi and Rathi et al described a patient with necrobiosis lipoidica that had erythematous, indurated and tender plaques with superficial ulceration that clinically mimicked cellulitis [15]. The lesions were not yellow or waxy and no telangiectasia was seen. Liapon and Mashkilleison et al reported a case of necrobiosis lipoidica in a non-diabetic patient that clinically resembled Degos' papulosis [16]. Alonso et al described a case of ulcerated necrobiosis lipoidica on the glans penis that was initially suspicious for squamous cell carcinoma [17]. The ulcer had red borders, a base that was erythematous, and a center that was necrotic. NL has also been reported in other unusual locations. Lynch et al described a case of atypical necrobiosis lipoidica as arcuate plaques that appeared on the face and scalp [18]. No cases of hyperkeratotic necrobiosis lipoidica, though, have been reported previously.

There are numerous treatments available for necrobiosis lipoidica, however, no modality is consistently effective and leads to complete resolution [6]. It is widely agreed upon that good diabetic glycemic control does not relate to control of NL [2].

\section{Conclusion}

This case illustrates a unique presentation of necrobiosis lipoidica. Not only were the plaques in unique locations, but one plaque clinically exhibited significant central hyperkeratosis as opposed to epidermal atrophy, which to the best of our knowledge has never been reported in the literature.

\section{References}

1. Oppenheim M. Eigentumlich disseminierte degeneration des bindegewebes der haut bie einem diabetiker. Z Hautkr. 19291930;32:179.

2. Lowitt MH, Dover JS. Necrobiosis lipoidica. J Am Acad Dermatol. 1991 Nov;25(5 Pt 1):735-48. Review. PubMed PMID: 1802895 .
3. Peyrí J, Moreno A, Marcoval J. Necrobiosis lipoidica. Semin Cutan Med Surg. 2007 Jun;26(2):87-9. Review. PubMed PMID: 17544959.

4. Wee SA, Possick P. Necrobiosis lipoidica. Dermatol Online J. 2004;10(3):18. PubMed PMID: 15748588.

5. Gottrup F, Karlsmark T. Leg ulcers: uncommon presentations. Clin Dermatol. 2005;23(6):601-11. Review. PubMed PMID: 16325069.

6. Izikson L, English JC. Noninfectious granulomatous diseases: an update. Adv Dermatol. 2006;22:31-53. Review. PubMed PMID: 17249294.

7. Boulton AJ, Cutfield RG, Abouganem D, Angus E, Flynn HW Jr, Skyler JS, Penneys NS. Necrobiosis lipoidica diabeticorum: a clinicopathologic study. J Am Acad Dermatol. 1988;18(3):530-7. PubMed PMID: 3351015.

8. Parra CA. Transepithelial elimination in necrobiosis lipoidica. $\mathrm{Br}$ J Dermatol. 1977;96(1):83-6. PubMed PMID: 843440.

9. Hammami H, Youssef S, Jaber K, Dhaoui MR, Doss N. Perforating necrobiosis lipoidica in a girl with type 1 diabetes mellitus: a new case reported. Dermatol Online J. 2008;14(7):11. Review. PubMed PMID: 18718195.

10. Abdulla FR, Sheth PB. A case of perforating necrobiosis lipoidica in an African American female. Dermatol Online J. 2008;14(7):10. PubMed PMID: 18718194.

11. De la Torre C, Losada A, Cruces MJ. Necrobiosis lipoidica: a case with prominent cholesterol clefting and transepithelial elimination. Am J Dermatopathol. 1999;21(6):575-7. PubMed PMID: 10608254.

12. Pestoni C, Ferreirós MM, de la Torre C, Toribio J. Two girls with necrobiosis lipoidica and type I diabetes mellitus with transfollicular elimination in one girl. Pediatr Dermatol. 2003;20(3):211-4. PubMed PMID: 12787268.

13. McDonald L, Zanolli MD, Boyd AS. Perforating elastosis in necrobiosis lipoidica diabeticorum. Cutis. 1996;57(5):336-8. Review. PubMed PMID: 8726715.

14. Michaels BD, Mullinax KA, Wells MJ, Stetson CL. Tuberous necrobiosis lipoidica. Arch Dermatol. 2007;143(4):546-8. PubMed PMID: 17438196.

15. Joshi A, Rathi SK, Khanna N. Necrobiosis lipoidica mimicking cellulitis. Indian J Dermatol Venereol Leprol. 1997;63(3):191-2. PubMed PMID: 20944321.

16. Liapon AO, Mashkilleison AL, Mkhitarian AG. [Non-diabetic necrobiosis lipoidica clinically resembling Degos' papulosis]. Vestn Dermatol Venerol. 1985;(8):38-9. Russian. PubMed PMID: 4072386.

17. Alonso ML, Rios JC, Gonzalez-Beato MJ, et al. Necrobiosis lipoidica of the glans penis. Acta Derm Venereol. 2011;91(1):1056. PubMed PMID: 21103831.

18. Lynch M, Callagy G, Mahon S, Murphy LA. Arcuate plaques of the face and scalp. Atypical necrobiosis lipoidica (ANL) of the face and scalp. Clin Exp Dermatol. 2010;35(7):799-800. doi: 10.1111/j.1365-2230.2010.03831.x. PubMed PMID:20831607. 